\title{
Clinical value and potential pathways of miR-183-5p in bladder cancer: A study based on miRNA-seq data and bioinformatics analysis
}

\author{
JIA-MIN GAO ${ }^{1-4 *}$, LIN-ZHEN HUANG ${ }^{1,2,4,5^{*}}$, ZHI-GUANG HUANG ${ }^{1,2,4,5}$ and RONG-QUAN HE HE $^{1-4}$ \\ ${ }^{1}$ Center for Genomic and Personalized Medicine, Guangxi Medical University; \\ ${ }^{2}$ Guangxi Collaborative Innovation Center for Genomic and Personalized Medicine; ${ }^{3}$ Department of Biochemistry, \\ Guangxi Medical University; ${ }^{4}$ Guangxi Key Laboratory for Genomic and Personalized Medicine, \\ ${ }^{5}$ Guangxi Collaborative Innovation Center for Biomedicine, Guangxi Medical University, \\ Nanning, Guangxi Zhuang Autonomous Region 530021, P.R. China
}

Received October 13, 2017; Accepted January 29, 2018

DOI: $10.3892 / \mathrm{ol} .2018 .7967$

\begin{abstract}
The clinicopathological value and exploration of the potential molecular mechanism of microRNA-183-5p (miR$183-5 \mathrm{p})$ have been investigated in various cancers; however, to the best of the author's knowledge, no similar research has been reported for bladder cancer. In the present study, it was revealed that the expression level of miR-183-5p was notably increased in bladder cancer tissues compared with adjacent non-cancerous tissues $(\mathrm{P}=0.001)$ and was markedly increased in the tissue samples of papillary, pathological T stage (T0-T2) and pathological stage (I-II) compared with tissue samples of their counterparts $(\mathrm{P}=0.05)$, according to data from The Cancer Genome Atlas. Receiver operating characteristic analysis revealed the robust diagnostic value of miR-183-5p for distinguishing bladder cancer from non-cancerous bladder tissues (area under curve $=0.948 ; 95 \%$ confidence interval: 0.919 0.977). Amplification and deep deletion of miR-183-5p were indicated by cBioPortal, accounting for $1 \%$ (4/412) of bladder cancer cases. Data from YM500v3 demonstrated that compared with other cancers, bladder cancer exhibited high expression levels of miR-183-5p, and miR-183-5p expression in primary solid tumors was much higher compared with solid normal tissues. A meta-analysis indicated that miR183-5p was more highly expressed in bladder cancer samples compared with normal counterparts. A total of 88 potential
\end{abstract}

Correspondence to: Dr Rong-Quan He, Center for Genomic and Personalized Medicine, Guangxi Medical University, 22 Shuangyong Road, Nanning, Guangxi Zhuang Autonomous Region 530021, P.R. China

E-mail: 254199854@qq.com

*Contributed equally

Key words: bladder cancer, miR-183-5p, amplification, diagnosis, hub genes target genes of miR-183-5p were identified, 13 of which were discerned as hub genes by protein-protein interaction. The epithelial-to-mesenchymal transition pathway was the most significantly enriched pathway by FunRich $(\mathrm{P}=0.0001)$. In summary, miR-183-5p may participate in the tumorigenesis and development of bladder cancer via certain signaling pathways, particularly the epithelial-to-mesenchymal transition pathway. However, the exact molecular mechanism of miR$183-5 \mathrm{p}$ in bladder cancer must be validated by in vitro and in vivo experiments.

\section{Introduction}

Due to the high mortality and recurrence, bladder cancer (BC) remains one of the most frequently appearing cancer of the urinary system (1). In America, 79,030 new patients with BC will be diagnosed in 2017, including 60,490 males and 18,540 females (2). Although there has been huge progress in therapeutic methods, such as cystectomy and adjuvant treatments, BC occupies one of the most common cancers with a high mortality and recurrence rate worldwide (1). Among the patients with recurrent $\mathrm{BC}$, more than one-tenth continue to develop into higher phases, such as muscle invasion and metastasis (3-5). The discovery of cancer at an advanced stage could lead to a poor prognosis. It is a prioritized event to explore the exact mechanism of $\mathrm{BC}$ to improve the sensitivity and specificity of early diagnosis. In recent years, evidence accumulation in the knowledge of molecular biology and application of bioinformatics has provided good opportunities to understand $\mathrm{BC}$ comprehensively via bioinformatic analysis, such as the application of microRNAs (miRNAs) (6-8).

miRNAs, a type of short non-coding RNA 22 nucleotides in length, facilitate mRNA degradation by sequence-specific combination with mRNA, providing new strategies on diagnosis and treatment of cancers (9-12). miRNAs have been found to participate in the expression regulation of hub genes related to the development and progression of tumors, including BC (13-16). The abnormally expressed and genetically altered miRNAs have been reported to be involved in the 
biological process of BC, including miR-199a-5p, miR-1-3p, miR-9, miR-182 and miR-200b (17-19).

miR-183-5p, located on chromosome 7q32.2, has been studied in various types of cancers, such as human breast cancer (20), esophageal squamous cell carcinoma (21), esophageal squamous cell carcinoma (22), gastric cancer (23), human pancreatic adenocarcinoma (24) and melanoma (25). The expression of miR-183 in BC patients was higher in tissues (26-28) and serum (29) and showed a moderate value of the BC diagnosis (27). However, no functional study of miR-183-5p in BC has been reported previously. Most of the published studies on miR-183-5p tended to focus on the higher expression of miR-183-5p in samples from patients with BC, including tissues, urine and serum, than in samples from normal individuals, or the diagnostic efficiency of miR-183-5p. However, the clinical significance, as well as the promising target genes of miR-183-5p in BC, needs to be explored (26-29). In addition, the studies mentioned above were based on a small scale of BC patient cohorts, and big data analysis was needed to uncover the real role of miR-183-5p in BC.

Therefore, in the present study, we first attempted to investigate the clinical significance of the expression level and genetic alteration of miR-183-5p in BC based on the data from The Cancer Genome Atlas (TCGA; https://cancergenome.nih.gov/), cBioPortal for Cancer Genomics (http://www.cbioportal.org/), Gene Expression Omnibus (GEO, https://www.ncbi.nlm.nih.gov/geo/), and YM500v3 (http://driverdb.tms.cmu.edu.tw/ym500v3/). In addition, we identified potential target genes of miR-183-5p via differential expressed genes calculated by RNA-seq data from TCGA, predicting platforms and gene profiling post miR-183-5p overexpression in vitro. Further bioinformatic analyses, including the enrichment of functional annotation and biological pathway analyses, were performed to explore the possible roles of miR$183-5 \mathrm{p}$ in the tumorigenesis and progression of BC.

\section{Materials and methods}

The work flow of the present study is shown in Fig. 1. Firstly, we evaluated the clinical significance of miR-183-5p in BC based on data from TCGA, cBioPortal, YM500v3 and PubMed. Secondly, the potential molecular mechanism of miR-183-5p in $\mathrm{BC}$ was explored via bioinformatic analysis with potential target genes overlapped with predicting target genes, lowexpression genes based on RNA-seq data from TCGA and downregulated genes from Gene Expression Omnibus (GEO).

Data acquisition and analysis. The miRNA sequencing data of miR-183 and clinical information of patients with $\mathrm{BC}$ were obtained from TCGA and contained 412 cases and 19 paracarcinoma tissues of counterparts as controls $(30,31)$. Only 409 cases possessed the miRNA sequencing data and clinical information. The clinical information and follow-up data of these cases, including sex, body mass index (BMI), primary therapy outcome, pack number of cigarettes smoked per year, primary therapy outcome, diagnosis subtype, lymphovascular invasion, pathologic $\mathrm{T}$ stage, pathologic $\mathrm{N}$ stage, pathologic $\mathrm{M}$ stage, pathologic stage and new tumor events after initial treatment were also downloaded to analyze the correlation between miR-183 expression and clinical parameters (Table I). Receiver operator characteristic curve (ROC) and Kaplan-Meier (K-M) analyses were used to assess the diagnostic and prognostic roles of miR-183.

Furthermore, the expression data and prognostic analysis of miR-183-5p were provided from database of YM500v3 (http://driverdb.tms.cmu.edu.tw/ym500v3/). The genetic alteration of miR-183 was validated from the cBioPortal database (http://www.cbioportal.org/).

Meta-analysis of miR-183 expression based on the data from TCGA, GEO and the literature. A resourceful GEO database could provide strong support in mining the expression data of miRNAs in human cancers. Therefore, we also searched the GEO database to mine the miR-183-5p expression level in BC. The following terms were used for searching: (bladder OR urothelial OR urinary OR urogenital) AND (cancer OR carcinoma OR tumor OR neoplasm* OR malignant*). The miR-183-5p expression data were extracted from $\mathrm{BC}$ and relevant controls.

A comprehensive search in several main literary databases worldwide, including PubMed, Chinese VIP, CNKI, WanFang database, SinoMed, Embase, Web of science, Science Direct and Wiley Online Library, was performed for the validation of the miR-183 expression level, up to July 1, 2017. The following terms were used for searching: (bladder OR urothelial OR urinary OR urogenital) AND (cancer OR carcinoma OR tumor OR neoplasm* OR malignant*) AND (MicroRNA183 OR miRNA183 OR miR183 OR miR-183 OR miRNA-183 OR microRNA-183 OR 'microRNA183' OR 'miRNA1' OR 'miR183' OR miR-183-5p OR miRNA-183-5p OR microRNA-183-5p).

Prediction of the prospective target genes of miR-183-5p. The prediction of miR-183-5p target genes was conducted with different bioinformatics tools, including miRWalk, MicroT4, miRanda, miRBridge, miRDB, miRMap, miRNAMap, PICTAR2, PITA, RNA22, RNAhybrid, TargetScan. Only 7,421 genes appearing for over 4 times among 12 platforms were regarded as potential target genes of miR-183-5p.

Potentially related genes of miR-183-5p in BC cells as detected by microarray. According to the information provided by GSE24782 microarray, a few human cancer cell lines, including BOY, T24, A498, PC3, DU145, FaDu, SAS, HSC3 and IMC3, were transfected with different miRNAs (miR-183-5p, miR-218, miR-145, miR-1 and miR-874). Based on the functional mechanism of miRNA, low-expression genes with a fold change (FC) $<0.85$ after transfected with miR-183-5p in BOY and T24 cells were regarded as potential target genes of miR-183-5p. A total of 3,163 genes were selected for further analysis.

Selection of low-expression genes based on RNA-seq dataset from TCGA. The RNA-seq dataset from TCGA contained 60,483 mRNAs, which were then used for the analysis of the differential expression with the $\mathrm{R}$ package of edgeR $(32,33)$. Differentially expressed genes with the expression data missing in $>10 \%$ samples were excluded. Due to the high expression of miR-183 in tumor tissues, low-expression genes were selected as the candidates of target genes of miR-183-5p. Therefore, 2,918 low-expression genes with $\log 2 \mathrm{FC}<-1$ were included.

Protein-protein interaction (PPI) analysis, Geneontology $(G O)$ and biological pathway. PPI was conducted to identify the hub 


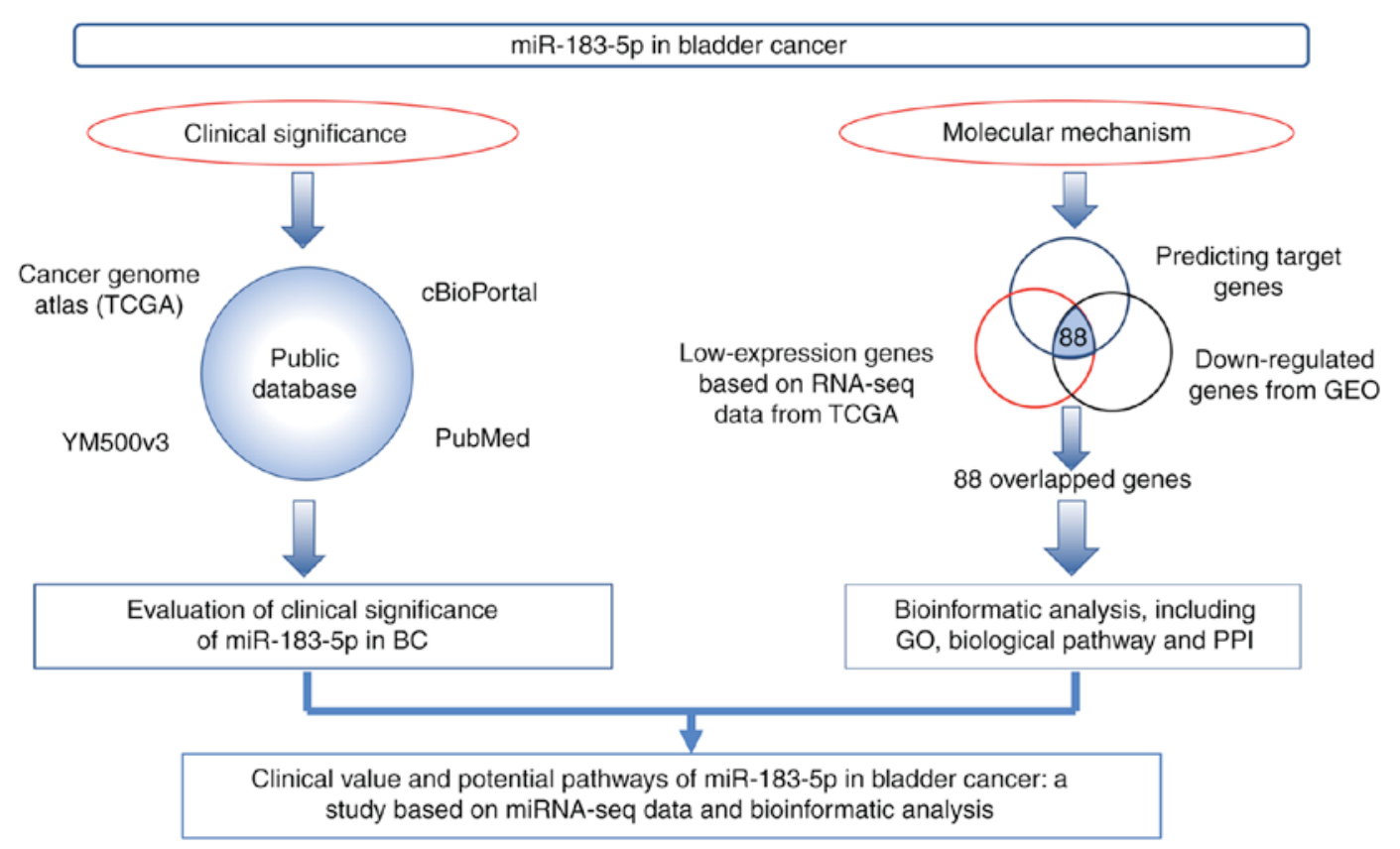

Figure 1. Work flow of the clinical value evaluation and bioinformatical analysis for miR-183-5p in bladder cancer.

genes by STRING: Functional protein association networks (https://string-db.org/). Furthermore, to study the prospective biological effects of miR-183-5p in BC, the potential target genes of miR-183-5p were sent for GO and biological pathway analyses, which was performed via FunRich: Functional Enrichment analysis tool $(34,35)$ (http://www.funrich.org/).

Moreover, to validate the reliability of the potential target genes of miR-183-5p, correlation analysis between the mRNA expression data of the prospective target genes of miR-183-5p enriched in the first pathway of the biological pathway and miR-183-5p expression data were performed. The comparisons of potential target genes between $\mathrm{BC}$ and non-cancerous tissues were also carried out.

Statistical analysis. The miR-183-5p expression data are displayed as the means \pm standard deviation (SD). Student's t-test for independent samples was performed to evaluate the relationship between miR-183 and clinical parameters. Pearson correlation analysis and Student's t-test were performed for the verification of genes significantly enriched in biological pathways. $\mathrm{P}<0.05$ was considered to indicate a statistically significant difference.

\section{Results}

Clinical significance of $m i R-183$. Due to the lack of expression data of mature miR-183-5p in the dataset of TCGA, the comparison of the stem-loop mir-183 expression level between $\mathrm{BC}$ and adjacent non-cancerous tissues was provided. The miR-183 expression level in BC tissues was notably higher than that in adjacent tissues (Fig. 2A; Table I). High expression of miR-183 was notably associated with the papillary subtype ( $\mathrm{t}=-3.353, \mathrm{P}=0.001)$, low pathologic $\mathrm{T}$ stage $(\mathrm{t}=2.106$, $\mathrm{P}=0.036)$, and early pathologic stage $(\mathrm{t}=2.533, \mathrm{P}=0.012)$. However, no remarkable differences were found between miR-183 expression and sex, BMI, primary therapy outcome, pack number of cigarettes smoked per year (mean), primary therapy outcome, lymphovascular invasion present, pathologic $\mathrm{N}$ stage, pathologic $\mathrm{M}$ stage or new tumor event after initial treatment (Table I).

ROC curve analysis showed that the area under the curve (AUC) was 0.948 (95\% CI: 0.919-0.977) with 83.6\% sensitivity and $100 \%$ specificity (Fig. 2B), indicating that a high expression level of miR-183 may be an ideal marker for BC diagnosis. Furthermore, the K-M curve uncovered that no significant difference in the survival time was noted between patients in the low and high miR-183 expression groups $(\mathrm{P}=0.861)$ (Fig. 2C).

The expression of miR-183-5p in primary solid tumors were much higher than that in solid normal tissues (Fig. 2D), which was consistent with the result from TCGA (Fig. 2A). The miR-183-5p expression data in various cancers were provided in YM500v3 (Fig. 2E). Compared with other cancers, BC exhibited higher expression levels of miR$183-5 \mathrm{p}$. This finding again confirmed that there was no significant prognostic value of miR-183-5p in patients with BC (Fig. 2F).

The data from cBioPortal revealed that miR-183 contained two kinds of genetic alterations, including amplification and deep deletion, accounting for 1\% (4/412) of patients with BC (Fig. 2G). In addition, no prominent correlation was found between miR-183 alteration and the outcome of $\mathrm{BC}$ patients, including overall survival or disease-free survival (Fig. 2H and I).

miR-183-5p expression level from GEO and literatures. A total of 16 microarrays were obtained from GEO, including GSE20414, GSE20418, GSE2564, GSE31616, GSE31617, GSE36121, GSE39067, GSE39093, GSE40355, GSE48008, GSE50894, GSE59483, GSE81201, GSE83586, GSE84525 and GSE86411. Eventually, only GSE39093 was eligible, and the data were used for recalculation. The expression level 


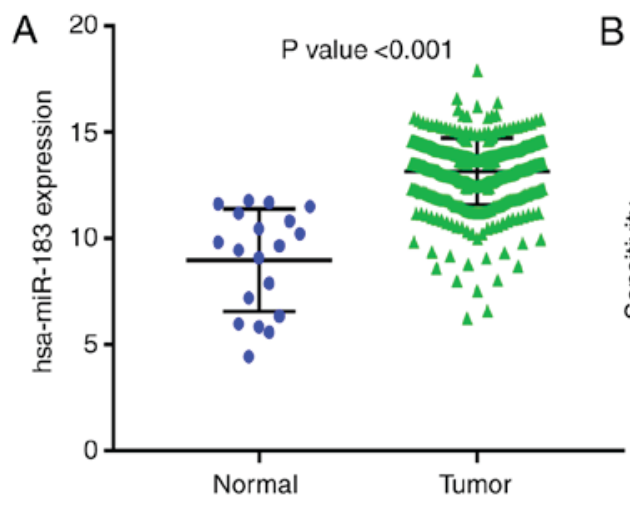

D

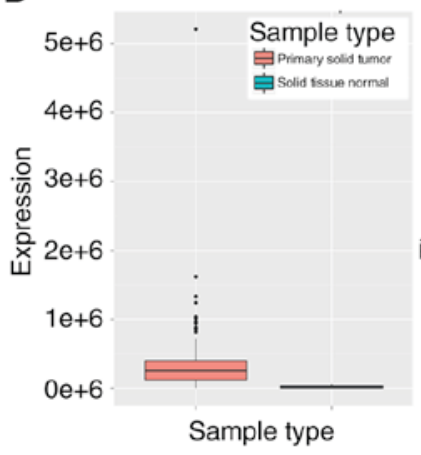

$B$

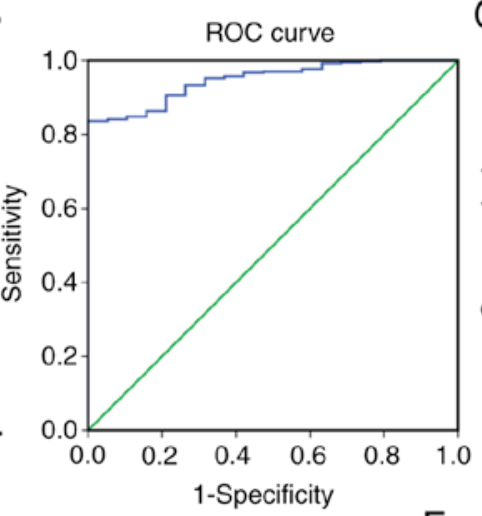

C

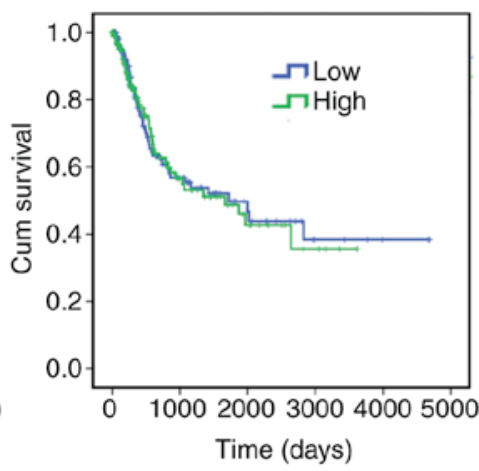

E

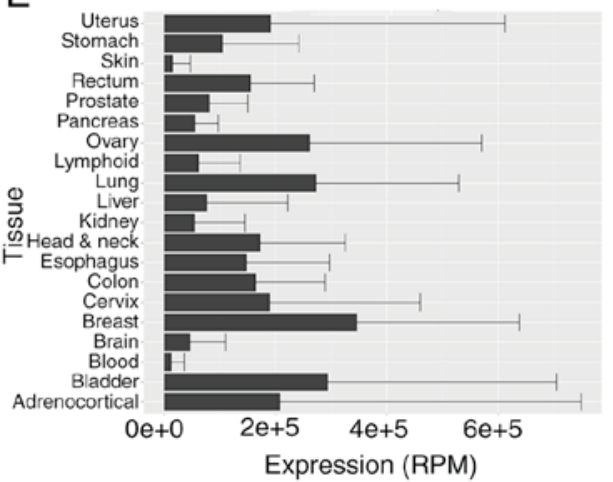

F

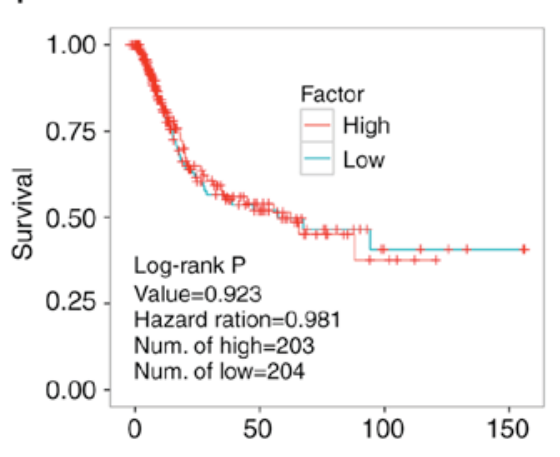

$\mathrm{G}$ Altered in $4(1 \%)$ of 412 sequenced cases/patients ( 412 total) miR183 Genetic alternation

$\mathrm{H}$

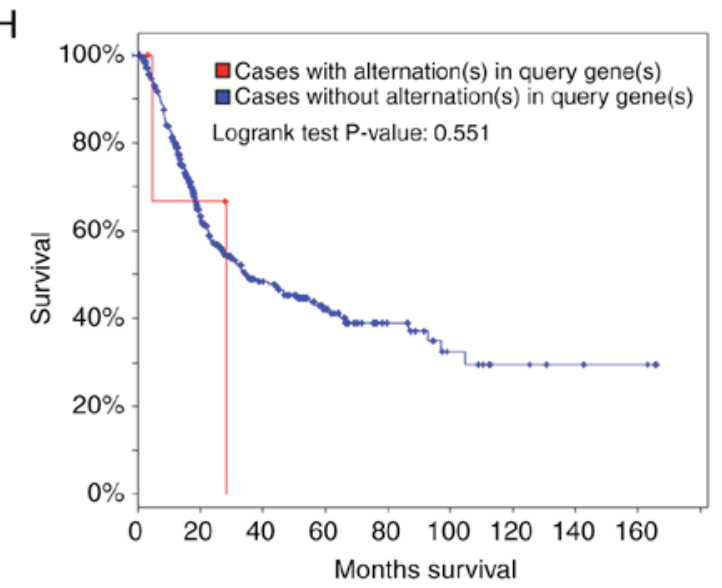

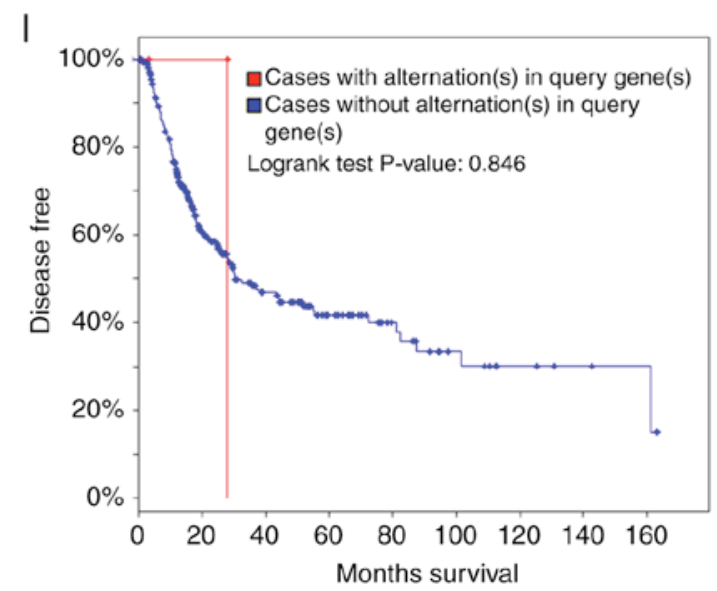

Figure 2. Clinical value of miR-183 in bladder cancer (BC) with different databases. (A) Expression data of miR-183-5p in normal and tumor tissues from TCGA (the $y$-axis represents $\log 2$ scaled). (B) Receiver operating characteristic (ROC) curve analysis of miR-183 to identify BC tissues from non-tumor bladder tissues based on TCGA dataset. (C) Kaplan-Meier survival curve of miR-183 for patients with BC. (D) Expression level of miR-183-5p in primary solid tumor and solid normal tissue from YM500v3 (http://driverdb.tms.cmu.edu.tw/ym500v3/). (E) Expression level of miR-183-5p in different cancers from YM500v3. (F) Relationship between miR-183-5p expression and overall survival by K-M curve analysis from YM500v3. (G) Genetic alterations of miR-183 in BC from cBioPortal (http://www.cbioportal.org). (H) Relationship between the alteration of miR-183 and overall survival from cBioPortal. (I) Disease-free survival from cBioPortal.

of miR-183-5p (4.216 \pm 0.485$)$ in $10 \mathrm{BC}$ tissue samples was moderately higher than that in the 10 normal counterparts (3.825 $\pm 0.460, \mathrm{P}>0.05)$ (Fig. 3A). A comprehensive search was performed in several literature databases; however, only one study provided normalized expression data. In detail, the expression of miR-183-5p in 104 urothelial carcinomas
(4.225 \pm 0.414$)$ was significantly higher than that in 31 normal bladder epitheliums (1.224 $\pm 0.224, \mathrm{P}<0.0001)$ (Fig. 3B) (27). All of the eligible expression data of miR-183-5p extracted from TCGA, one GEO microarray and one literature research provided an overall SMD of $3.76(0.34-7.19)$ as analyzed by STATA software (Fig. 3C), suggesting that miR-183-5p was 
Table I. Correlation between miR-183 expression and clinical parameters.

\begin{tabular}{|c|c|c|c|c|}
\hline \multirow[b]{2}{*}{ Clinical parameters } & \multicolumn{4}{|c|}{ miR-183 expression } \\
\hline & $\mathrm{n}$ & Mean \pm SD & $\mathrm{t}$ & P-value \\
\hline Tissue & & & -7.489 & $<0.001$ \\
\hline Adjacent & 19 & $8.975 \pm 2.409$ & & \\
\hline Tumor & 403 & $13.155 \pm 1.562$ & & \\
\hline Sex & & & -0.151 & 0.880 \\
\hline Male & 298 & $13.148 \pm 1.561$ & & \\
\hline Female & 105 & $13.175 \pm 1.572$ & & \\
\hline BMI & & & 0.591 & 0.555 \\
\hline$\leq 25$ & 146 & $13.188 \pm 1.381$ & & \\
\hline$>25$ & 209 & $13.088 \pm 1.683$ & & \\
\hline Primary therapy outcome & & & 0.899 & 0.370 \\
\hline $\mathrm{CR}+\mathrm{PR}+\mathrm{SD}$ & 187 & $13.175 \pm 1.533$ & & \\
\hline PD & 42 & $12.938 \pm 1.613$ & & \\
\hline Pack number of cigarettes smoked per year & & & 1.513 & 0.132 \\
\hline$<39.003$ & 132 & $13.225 \pm 1.486$ & & \\
\hline$\geq 39.003$ & 88 & $12.886 \pm 1.824$ & & \\
\hline Primary therapy outcome & & & 0.899 & 0.370 \\
\hline $\mathrm{CRR}+\mathrm{PRR}+\mathrm{SD}$ & 187 & $13.175 \pm 1.533$ & & \\
\hline PD & 42 & $12.938 \pm 1.613$ & & \\
\hline Diagnosis subtype & & & -3.353 & 0.001 \\
\hline Non-papillary & 270 & $12.993 \pm 1.700$ & & \\
\hline Papillary & 129 & $13.486 \pm 1.186$ & & \\
\hline Lymphovascular invasion & & & -1.051 & 0.294 \\
\hline No & 130 & $13.054 \pm 1.668$ & & \\
\hline Yes & 147 & $13.253 \pm 1.488$ & & \\
\hline Pathologic T stage & & & 2.106 & 0.036 \\
\hline T0-T2 & 123 & $13.333 \pm 1.502$ & & \\
\hline $\mathrm{T} 3-\mathrm{T} 4$ & 247 & $12.966 \pm 1.614$ & & \\
\hline Pathologic N stage & & & 1.369 & 0.172 \\
\hline N0-N1 & 278 & $13.208 \pm 1.553$ & & \\
\hline N2-N3 & 84 & $12.948 \pm 1.430$ & & \\
\hline Pathologic M stage & & & -0.925 & 0.356 \\
\hline M0 & 193 & $13.515 \pm 1.317$ & & \\
\hline M1 & 10 & $13.921 \pm 1.975$ & & \\
\hline Pathologic stage & & & 2.533 & 0.012 \\
\hline Stage I-II & 132 & $13.420 \pm 1.445$ & & \\
\hline Stage III-IV & 269 & $13.017 \pm 1.604$ & & \\
\hline New tumor event after initial treatment & & & 0.864 & 0.388 \\
\hline No & 224 & $13.168 \pm 1.488$ & & \\
\hline Yes & 69 & $12.987 \pm 1.619$ & & \\
\hline
\end{tabular}

BMI, body mass index; CRR, complete remission/response; PRR, partial remission/response; SD, stable disease; PD, progressive disease.

more highly expressed in samples from $\mathrm{BC}$ than in those from normal counterparts. The source of patients with BC and different detection methods may lead to strong heterogeneity.
Identification of the potential target genes of miR-183-5p. In the present study, the overlapped genes from 3 subsets of genes, including predicted target genes, related potential target genes of miR-183-5p from GEO and low-expression genes from 
Table II. A total of 88 potential target genes of miR-183-5p.

\begin{tabular}{|c|c|c|c|c|c|}
\hline Ensemble ID & Gene name & Ensemble ID & Gene name & Ensemble ID & Gene name \\
\hline ENSG00000163431 & LMOD1 & ENSG00000138685 & FGF2 & ENSG00000140450 & ARRDC4 \\
\hline ENSG00000118496 & FBXO30 & ENSG00000136842 & TMOD1 & ENSG00000135269 & TES \\
\hline ENSG00000102271 & KLHL4 & ENSG00000184985 & SORCS2 & ENSG00000163661 & PTX3 \\
\hline ENSG00000113196 & HAND1 & ENSG00000169554 & ZEB2 & ENSG00000108797 & CNTNAP1 \\
\hline ENSG00000100784 & RPS6KA5 & ENSG00000144655 & CSRNP1 & ENSG00000163083 & INHBB \\
\hline ENSG00000104447 & TRPS 1 & ENSG00000167483 & FAM129C & ENSG00000105835 & NAMPT \\
\hline ENSG00000140090 & SLC24A4 & ENSG00000064309 & $\mathrm{CDON}$ & ENSG00000083067 & TRPM3 \\
\hline ENSG00000017427 & IGF1 & ENSG00000159167 & STC1 & ENSG00000152217 & SETBP1 \\
\hline ENSG00000183454 & GRIN2A & ENSG00000152102 & FAM168B & ENSG00000104313 & EYA1 \\
\hline ENSG00000143878 & RHOB & ENSG00000134531 & EMP1 & ENSG00000151929 & BAG3 \\
\hline ENSG00000105974 & CAV1 & ENSG00000166974 & MAPRE2 & ENSG00000007312 & CD79B \\
\hline ENSG00000173334 & TRIB1 & ENSG00000105784 & RUNDC3B & ENSG00000138944 & KIAA1644 \\
\hline ENSG00000188385 & JAKMIP3 & ENSG00000173068 & BNC2 & ENSG00000182168 & UNC5C \\
\hline ENSG00000095794 & CREM & ENSG00000188803 & SHISA6 & ENSG00000169083 & AR \\
\hline ENSG00000106829 & TLE4 & ENSG00000169504 & CLIC4 & ENSG00000163788 & SNRK \\
\hline ENSG00000187098 & MITF & ENSG00000058272 & PPP1R12A & ENSG00000004799 & PDK4 \\
\hline ENSG00000113448 & PDE4D & ENSG00000172399 & MYOZ2 & ENSG00000145861 & C1QTNF2 \\
\hline ENSG00000126351 & THRA & ENSG00000115252 & PDE1A & ENSG00000151892 & GFRA1 \\
\hline ENSG00000163328 & GPR155 & ENSG00000164741 & DLC1 & ENSG00000169946 & ZFPM2 \\
\hline ENSG00000178662 & CSRNP3 & ENSG00000066382 & MPPED2 & ENSG00000101333 & PLCB4 \\
\hline ENSG00000198961 & PJA2 & ENSG00000181773 & GPR3 & ENSG00000163171 & CDC42EP3 \\
\hline ENSG00000018408 & WWTR1 & ENSG00000140416 & TPM1 & ENSG00000107968 & MAP3K8 \\
\hline ENSG00000058668 & ATP2B4 & ENSG00000073910 & FRY & ENSG00000136267 & DGKB \\
\hline ENSG00000018625 & ATP1A2 & ENSG00000107562 & CXCL12 & ENSG00000126524 & SBDS \\
\hline ENSG00000136158 & SPRY2 & ENSG00000112320 & SOBP & ENSG00000091831 & ESR1 \\
\hline ENSG00000134201 & GSTM5 & ENSG00000142627 & EPHA2 & ENSG00000079308 & TNS1 \\
\hline ENSG00000118922 & KLF12 & ENSG00000058866 & DGKG & ENSG00000131016 & AKAP12 \\
\hline ENSG00000186354 & C9orf47 & ENSG00000162616 & DNAJB4 & ENSG00000131018 & SYNE1 \\
\hline ENSG00000078687 & TNRC6C & ENSG00000157368 & IL34 & ENSG00000146151 & HMGCLL1 \\
\hline ENSG00000067900 & ROCK1 & & & & \\
\hline
\end{tabular}

TCGA, were regarded as the potential target genes of miR183-5p. Finally, 88 overlapped genes were obtained (Table II).

Bioinformatic analyses of the target genes of miR-183-5p. As shown in Fig. 4, hub genes, which contained $>3$ connected lines, were identified, including estrogen receptor 1 (ESR1), melanogenesis-associated transcription factor (MITF), androgen receptor (AR), C-X-C motif chemokine ligand 12 (CXCL12), insulin-like growth factor 1 (IGF1), caveolin 1 (CAV1), DLC1 Rho GTPase activating protein (DLC1), fibroblast growth factor 2 (FGF2), EPH receptor A2 (EPHA2), Rho associated coiled-coil containing protein kinase 1 (ROCK1), Ras homolog family member B (RHOB), phospholipase C beta 4 (PLCB4) and tropomyosin 1 (TPM1) (single genes without connections are not shown) (Fig. 4).

The overlapped genes were also categorized in GO and biological pathway analyses using the software of FunRich: Functional Enrichment analysis tool. The top 5 pathways in molecularfunctions (MFs), such as cytoskeletal protein binding, protein threonine/tyrosine kinase activity, were displayed in Fig. 5A and Table III. In addition, the top 5 pathways of biological processes (BPs) (Fig. 5B) and cellular component (CC) were also noted (P-value <0.05) (Fig. 5C; Table III). Via the biological pathway analysis, we discovered that the epithelial-to-mesenchymal transition pathway was the most significantly enriched (P-value <0.00001) (Fig. 5D; Table III).

Validation of potential target genes enriched in the epithelial-to-mesenchymal transition pathway by mRNA expression data from TCGA. The mRNA expression data of potential target genes enriched in epithelial-to-mesenchymal transition pathway in $\mathrm{BC}$ and non-carcinomatous tissues, including zinc finger protein, FOG family member 2 (ZFPM2), A-kinase anchoring protein 12 (AKAP12), chloride intracellular channel 4 (CLIC4), zinc finger E-box binding homeobox 2 (ZEB2), basonuclin 2 (BNC2), caveolin 1 (CAV1), C-X-C motif chemokine ligand 12 (CXCL12), sine oculis binding protein homolog (SOBP), tensin 1 (TNS1), insulin-like growth factor 1 (IGF1), spectrin repeat containing nuclear envelope protein 1 (SYNE1), pentraxin 3 (PTX3), WW domain containing transcription regulator 1 (WWTR1), were extracted from TCGA. The correlation of the expression level between miR-183 

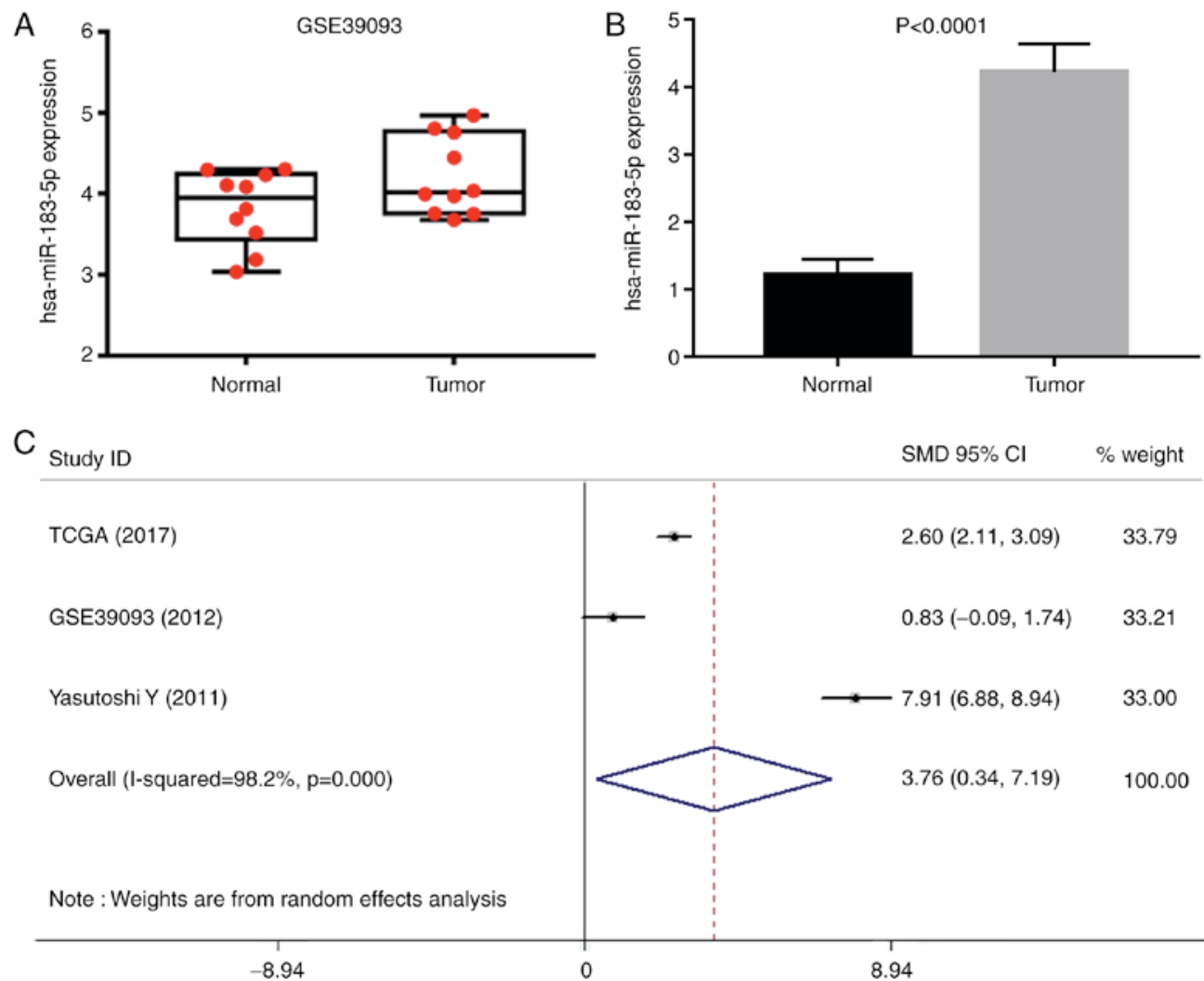

Figure 3. Meta-analysis of miR-183-5p. (A) Expression level of miR-183-5p from GSE39093. (B) miR-183-5p expression reported by Yamada et al (27). (C) Forest plot of the meta-analysis.

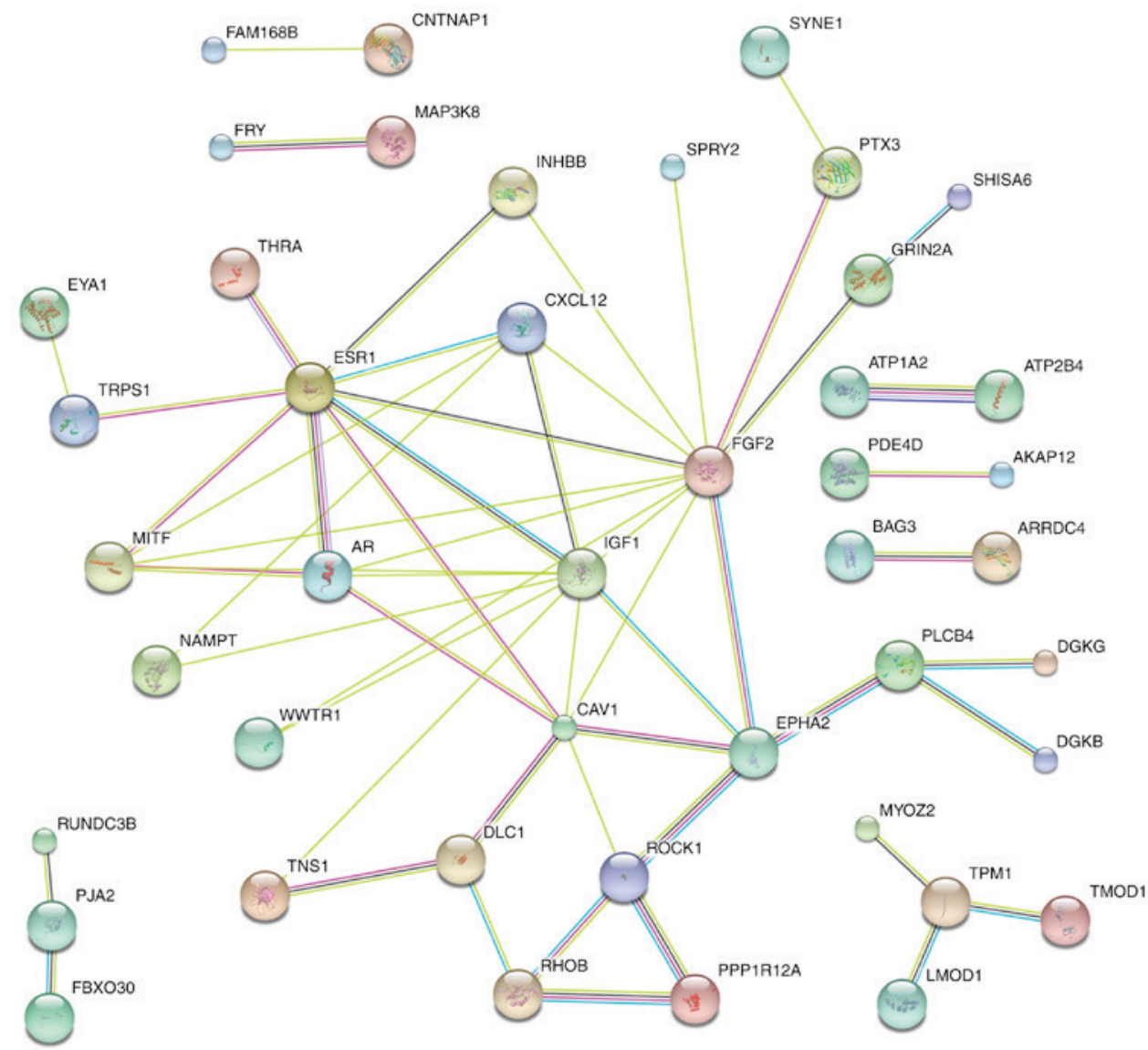

Figure 4. Protein-protein interaction (PPI) of the probable target genes of miR-183-5p in bladder cancer. The PPI network is pictured with the candidates target genes of miR-183-5p by STRING (http://string-db.org). Small nodes represent protein of unknown 3D structure; large nodes represent some 3D structure is known or predicted; colored nodes represent query proteins and first shell of interactors; white nodes represent second shell of interactors. 


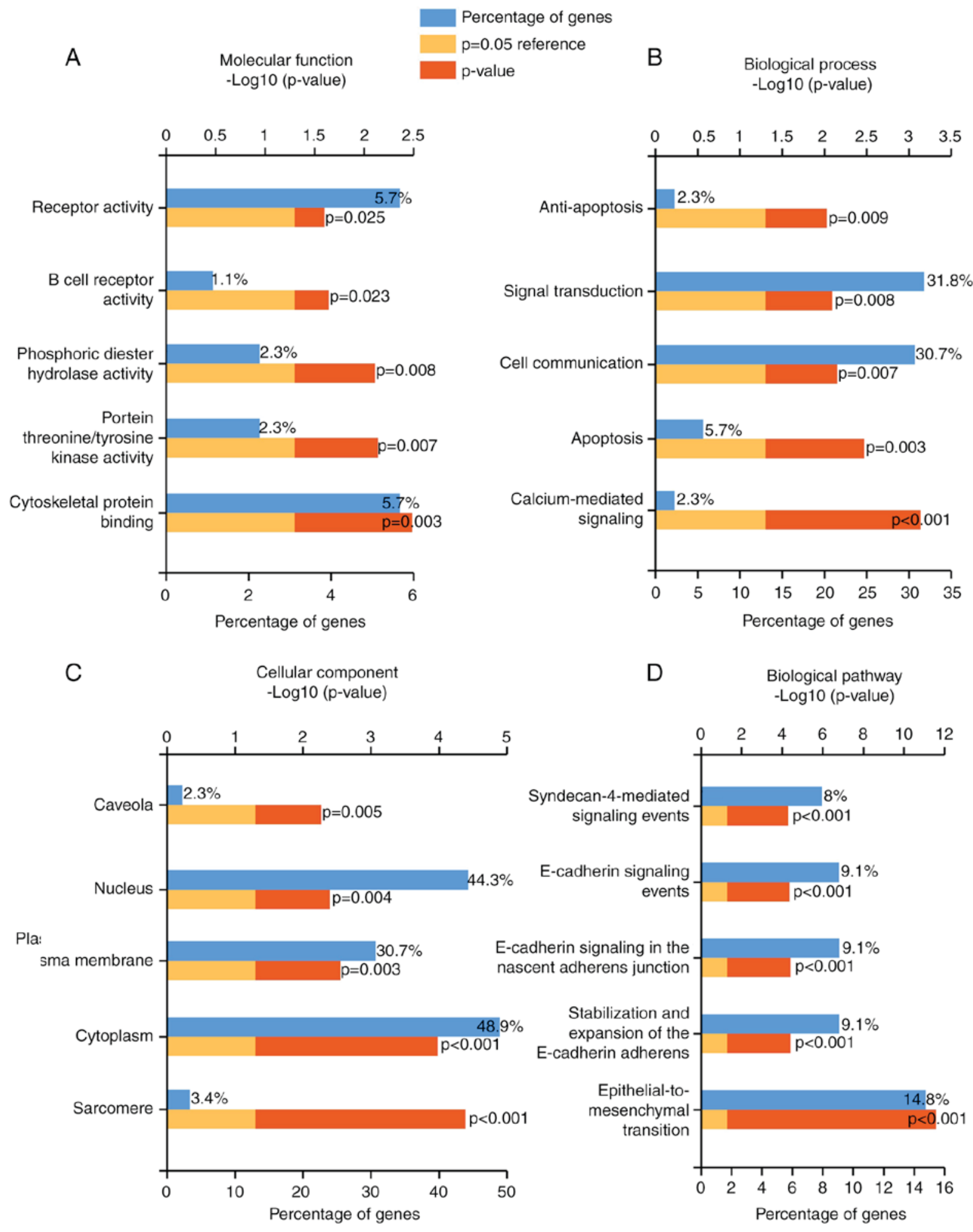

Figure 5. The top 5 enriched (A) molecular function (MF) pathways, (B) biological process (BP) pathways, (C) cellular component (CC) pathways and (D) biological pathways of candidate target genes of miR-183-5p in bladder cancer from GO analysis.

and potential target genes in BC tissues was evaluated by Pearson correlation analysis. The results showed that miR-183 expression in $\mathrm{BC}$ tissues were all notably correlated with the expression levels of prospective target genes, respectively (P-value <0.001) (Fig. 6). Furthermore, Student' t test was executed to compare the expression levels of candidate genes between the $\mathrm{BC}$ and non-carcinomatous tissues. Consequently, candidate gene expression data were all remarkably higher in $\mathrm{BC}$ than in non-carcinomatous tissues (Fig. 6; Table IV).

\section{Discussion}

In the present study, the clinical role of miR-183-5p in BC was first evaluated according to the data from miRNA sequencing 
Table III. Pathways of potential target genes of miR-183-5p in bladder cancer.

\begin{tabular}{|c|c|c|c|c|c|}
\hline Pathway & $\begin{array}{l}\text { No. of } \\
\text { genes in } \\
\text { the dataset }\end{array}$ & $\begin{array}{c}\text { Percentage } \\
\text { of genes }\end{array}$ & $\begin{array}{l}\text { Fold } \\
\text { enrichment }\end{array}$ & $\begin{array}{c}\text { P-value } \\
\text { (Hypergeometric } \\
\text { test) }\end{array}$ & Gene \\
\hline $\begin{array}{l}\text { MF: Cytoskeletal } \\
\text { protein binding }\end{array}$ & 5 & 5.682 & 5.021 & 0.003 & $\begin{array}{l}\text { TPM1; KLHL4; LMOD1; } \\
\text { TMOD1; MAPRE2 }\end{array}$ \\
\hline $\begin{array}{l}\text { MF: Protein threonine/ } \\
\text { tyrosine kinase activity }\end{array}$ & 2 & 2.273 & 15.679 & 0.007 & MAP3K8; TRIB1 \\
\hline $\begin{array}{l}\text { MF: Phosphoric diester } \\
\text { hydrolase activity }\end{array}$ & 2 & 2.273 & 15.139 & 0.008 & PDE1A; PDE4D \\
\hline $\begin{array}{l}\text { MF: B cell receptor } \\
\text { activity }\end{array}$ & 1 & 1.136 & 44.049 & 0.023 & CD79B \\
\hline MF: Receptor activity & 5 & 5.682 & 3.032 & 0.025 & $\begin{array}{l}\text { CDON; GFRA1; UNC5C; } \\
\text { CNTNAP1; SORCS2 }\end{array}$ \\
\hline $\begin{array}{l}\text { BP: Calcium-mediated } \\
\text { signaling }\end{array}$ & 2 & 2.273 & 48.744 & 0.001 & PLCB4; TRPM3 \\
\hline BP: Apoptosis & 5 & 5.682 & 4.976 & 0.003 & $\begin{array}{l}\text { CSRNP1; CSRNP3; BAG3; } \\
\text { SNRK; DLC1 }\end{array}$ \\
\hline BP: Cell communication & 27 & 30.682 & 1.589 & 0.007 & $\begin{array}{l}\text { STC1; CDC42EP3; GPR3; } \\
\text { PLCB4; SPRY2; EPHA2; } \\
\text { MAP3K8; RHOB; AR; CDON; } \\
\text { CXCL12; DGKB; GRIN2A; } \\
\text { PDE1A; PDE4D; TNS1; } \\
\text { UNC5C; CNTNAP1; GPR155; } \\
\text { IGF1; ROCK1; SORCS2; } \\
\text { FGF2; INHBB; TRIB1; } \\
\text { MYOZ2; RUNDC3B }\end{array}$ \\
\hline BP: Signal transduction & 28 & 31.818 & 1.556 & 0.008 & $\begin{array}{l}\text { STC1; CDC42EP3; GPR3; } \\
\text { PLCB4; SPRY2; EPHA2; } \\
\text { MAP3K8; RHOB; AR; CDON; } \\
\text { CXCL12; DGKB; GFRA1; } \\
\text { GRIN2A; PDE1A; PDE4D; } \\
\text { TNS1; UNC5C; CNTNAP1; } \\
\text { GPR155; IGF1; ROCK1; } \\
\text { SORCS2; FGF2; INHBB; } \\
\text { TRIB1; MYOZ2; RUNDC3B }\end{array}$ \\
\hline BP: Anti-apoptosis & 2 & 2.273 & 13.720 & 0.009 & NAMPT; IGF1 \\
\hline CC: Sarcomere & 3 & 3.409 & 43.816 & $<0.001$ & TPM1; SYNE1; MYOZ2 \\
\hline CC: Cytoplasm & 43 & 48.864 & 1.653 & $<0.001$ & $\begin{array}{l}\text { STC1; ATP2B4; CDC42EP3; } \\
\text { SPRY2; THRA; AKAP12; } \\
\text { ATP1A2; CLIC4; FBXO30; } \\
\text { MAP3K8; TLE4; TPM1; AR; } \\
\text { DGKB; DGKG; GFRA1; } \\
\text { GRIN2A; KLHL4; LMOD1; } \\
\text { MITF; NAMPT; PDE1A; } \\
\text { PDE4D; PPP1R12A; SBDS; } \\
\text { SETBP1; TMOD1; BAG3; } \\
\text { HAND1; IGF1; MAPRE2; } \\
\text { ROCK1; SYNE1; TRPM3; } \\
\text { ESR1; EYA1; TRIB1; } \\
\text { WWTR1; MYOZ2; CD79B; } \\
\text { GSTM5; RPS6KA5; DLC1 }\end{array}$ \\
\hline
\end{tabular}


Table III. Continued.

\begin{tabular}{|c|c|c|c|c|c|}
\hline Pathway & $\begin{array}{l}\text { No. of } \\
\text { genes in } \\
\text { the dataset }\end{array}$ & $\begin{array}{l}\text { Percentage } \\
\text { of genes }\end{array}$ & $\begin{array}{c}\text { Fold } \\
\text { enrichment }\end{array}$ & $\begin{array}{c}\text { P-value } \\
\text { (Hypergeometric } \\
\text { test) }\end{array}$ & Gene \\
\hline CC: Plasma membrane & 27 & 30.682 & 1.696 & 0.003 & $\begin{array}{l}\text { ATP2B4; GPR3; SPRY2; } \\
\text { AKAP12; ATP1A2; CLIC4; } \\
\text { EPHA2; RHOB; AR; CAV1; } \\
\text { CDON; DGKB; DGKG; } \\
\text { GFRA1; GRIN2A; PPP1R12A; } \\
\text { TNS1; UNC5C; CNTNAP1; } \\
\text { GPR155; SORCS2; TRPM3; } \\
\text { ESR1; FGF2; TES; SLC24A4; } \\
\text { CD79B }\end{array}$ \\
\hline CC: Nucleus & 39 & 44.318 & 1.458 & 0.004 & $\begin{array}{l}\text { STC1; ZFPM2; ATP2B4; } \\
\text { PLCB4; THRA; TRPS1; } \\
\text { AKAP12; ATP1A2; CLIC4; } \\
\text { CSRNP1; CSRNP3; TLE4; } \\
\text { TPM1; ZEB2; AR; BNC2; } \\
\text { CREM; GFRA1; MITF; } \\
\text { NAMPT; PDE4D; PPP1R12A; } \\
\text { SBDS; SETBP1; TMOD1; } \\
\text { CNTNAP1; HAND1; } \\
\text { MAPRE2; SYNE1; TRPM3; } \\
\text { ESR1; EYA1; FGF2; TRIB1; } \\
\text { KLF12; WWTR1; SNRK; } \\
\text { RPS6KA5; DLC1 }\end{array}$ \\
\hline $\begin{array}{l}\text { CC: Caveola } \\
\text { Biological pathway: }\end{array}$ & 2 & 2.273 & 18.292 & 0.005 & $\begin{array}{l}\text { CAV1; DLC1 } \\
\text { ZFPM2; AKAP12; CLIC4; }\end{array}$ \\
\hline $\begin{array}{l}\text { Epithelial-to- } \\
\text { mesenchymal } \\
\text { transition }\end{array}$ & 13 & 14.773 & 15.365 & $<0.001$ & $\begin{array}{l}\text { ZEB2; BNC2; CAV1; } \\
\text { CXCL12; SOBP; TNS1; } \\
\text { IGF1; SYNE1; PTX3; WWTR1 }\end{array}$ \\
\hline $\begin{array}{l}\text { Biological pathway: } \\
\text { Stabilization and } \\
\text { expansion of the } \\
\text { E-cadherin adherens } \\
\text { junction }\end{array}$ & 8 & 9.091 & 6.364 & $<0.001$ & $\begin{array}{l}\text { SPRY2; EPHA2; TLE4; AR; } \\
\text { GFRA1; MITF; IGF1; } \\
\text { ROCK1 }\end{array}$ \\
\hline $\begin{array}{l}\text { Biological pathway: } \\
\text { E-cadherin signaling } \\
\text { in the nascent adherens } \\
\text { junction }\end{array}$ & 8 & 9.091 & 6.364 & $<0.001$ & $\begin{array}{l}\text { SPRY2; EPHA2; TLE4; AR; } \\
\text { GFRA1; MITF; IGF1; ROCK1 }\end{array}$ \\
\hline $\begin{array}{l}\text { Biological pathway: } \\
\text { E-cadherin signaling } \\
\text { events }\end{array}$ & 8 & 9.091 & 6.250 & $<0.001$ & $\begin{array}{l}\text { SPRY2; EPHA2; TLE4; AR; } \\
\text { GFRA1; MITF; IGF1; ROCK1 }\end{array}$ \\
\hline $\begin{array}{l}\text { Biological pathway: } \\
\text { Syndecan-4-mediated } \\
\text { signaling events }\end{array}$ & 7 & 7.955 & 7.328 & $<0.001$ & $\begin{array}{l}\text { TLE4; AR; CAV1; CXCL12; } \\
\text { MITF; ROCK1; FGF2 }\end{array}$ \\
\hline
\end{tabular}

(TCGA, cBioPortal and YM5003v). miR-183-5p in BC contained two types of genetic alteration, gene amplification and deep deletion. Furthermore, pathway analyses uncovered that miR-183-5p could deeply affect multiple pathways and 

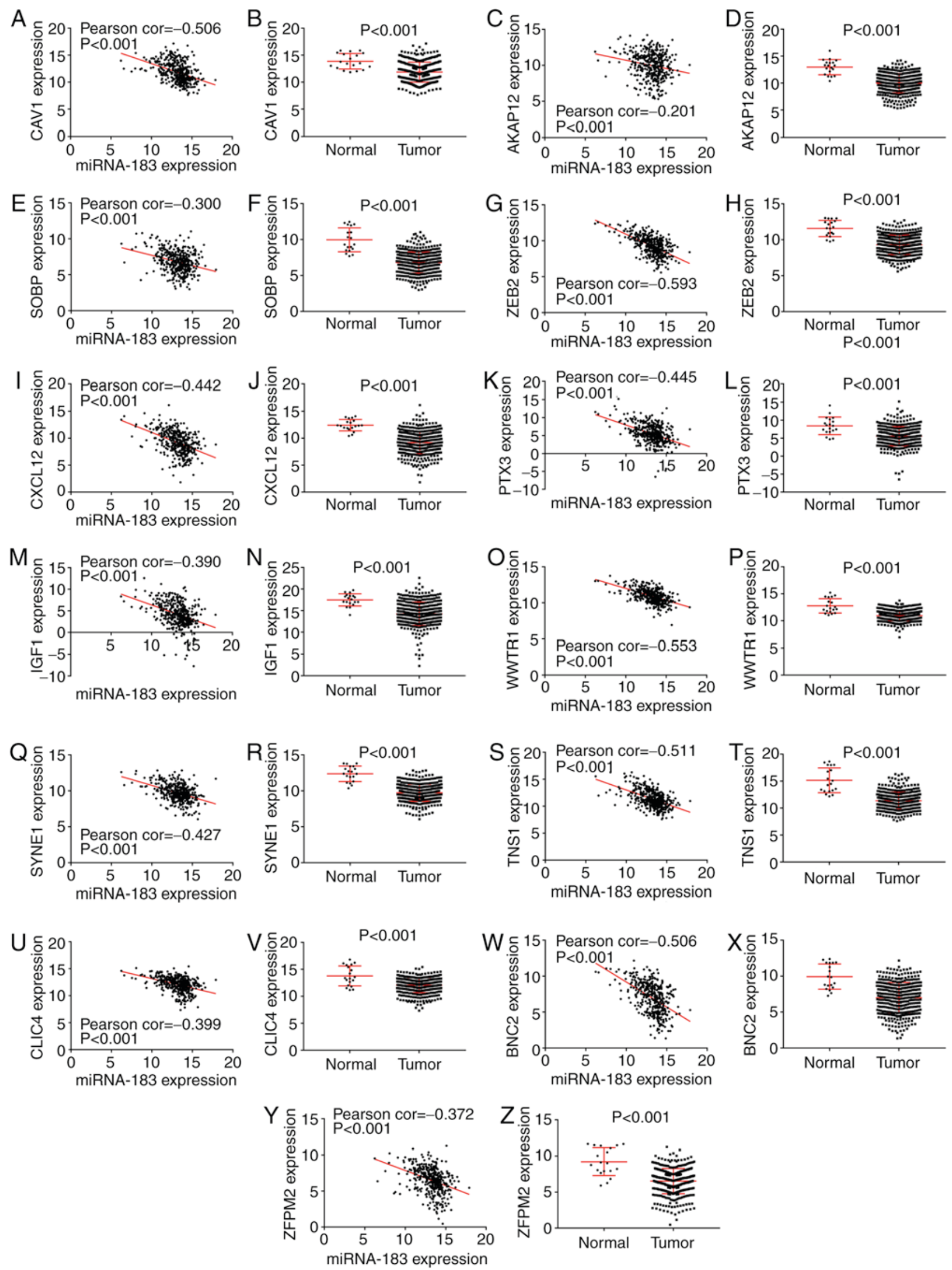

Figure 6. Validation of the potential target genes enriched in the epithelial-to-mesenchymal transition pathway by mRNA expression data from The Cancer Genome Atlas (TCGA), including (A and B) caveolin 1 (CAV1), (C and D) A-kinase anchoring protein 12 (AKAP12), (E and F) sine oculis binding protein homolog (SOBP), (G and H) zinc finger E-box binding homeobox 2 (ZEB2), (I and J) C-X-C motif chemokine ligand 12 (CXCL12), (K and L) pentraxin 3 (PTX3), (M and N) insulin-like growth factor 1 (IGF1), (O and P) WW domain containing transcription regulator 1 (WWTR1), (Q and R) spectrin repeat containing nuclear envelope protein 1 (SYNE1), (S and T) tensin 1 (TNS1), (U and V) chloride intracellular channel 4 (CLIC4), (W and X) basonuclin 2 (BNC2) and (Y and Z) zinc finger protein, FOG family member 2 (ZFPM2). 
Table IV. Comparison of the expression levels of potential target genes between normal bladder tissues and bladder cancer (BC) tissues.

\begin{tabular}{|c|c|c|c|c|c|c|}
\hline Gene & Group & $\mathrm{N}$ & Mean & Std. Deviation & P-value & Featurea \\
\hline \multirow[t]{3}{*}{ CAV1 } & & & & & $<0.001$ & Down \\
\hline & Normal & 19 & 13.87475 & 1.427754 & & \\
\hline & Tumor & 399 & 11.86889 & 1.857218 & & \\
\hline \multirow[t]{3}{*}{ AKAP12 } & & & & & $<0.001$ & Down \\
\hline & Normal & 19 & 12.96746 & 1.407823 & & \\
\hline & Tumor & 399 & 9.992088 & 1.793414 & & \\
\hline \multirow[t]{3}{*}{ SOBP } & & & & & $<0.001$ & Down \\
\hline & Normal & 19 & 9.964385 & 1.65852 & & \\
\hline & Tumor & 399 & 6.790578 & 1.474642 & & \\
\hline \multirow[t]{3}{*}{ ZEB2 } & & & & & $<0.001$ & Down \\
\hline & Normal & 19 & 11.57411 & 1.129419 & & \\
\hline & Tumor & 399 & 9.299417 & 1.35383 & & \\
\hline \multirow[t]{3}{*}{ CXCL12 } & & & & & $<0.001$ & Down \\
\hline & Normal & 19 & 12.41901 & 1.059525 & & \\
\hline & Tumor & 399 & 9.179279 & 2.088323 & & \\
\hline \multirow[t]{3}{*}{ PTX3 } & & & & & $<0.001$ & Down \\
\hline & Normal & 19 & 8.439694 & 2.440688 & & \\
\hline & Tumor & 399 & 5.515195 & 2.690033 & & \\
\hline \multirow[t]{3}{*}{ IGF1 } & & & & & $<0.001$ & Down \\
\hline & Normal & 19 & 7.488964 & 1.422601 & & \\
\hline & Tumor & 399 & 4.200803 & 2.727906 & & \\
\hline \multirow[t]{3}{*}{ WWTR1 } & & & & & $<0.001$ & Down \\
\hline & Normal & 19 & 12.77304 & 1.334257 & & \\
\hline & Tumor & 399 & 10.95718 & 0.966398 & & \\
\hline \multirow[t]{3}{*}{ SYNE1 } & & & & & $<0.001$ & Down \\
\hline & Normal & 19 & 12.37864 & 1.079004 & & \\
\hline & Tumor & 399 & 9.730599 & 1.186041 & & \\
\hline \multirow[t]{3}{*}{ TNS1 } & & & & & $<0.001$ & Down \\
\hline & Normal & 19 & 15.15798 & 2.307397 & & \\
\hline & Tumor & 399 & 11.36795 & 1.597026 & & \\
\hline \multirow[t]{3}{*}{ CLIC4 } & & & & & $<0.001$ & Down \\
\hline & Normal & 19 & 13.79678 & 1.851609 & & \\
\hline & Tumor & 399 & 12.06632 & 1.372628 & & \\
\hline \multirow[t]{3}{*}{$\mathrm{BNC} 2$} & & & & & $<0.001$ & Down \\
\hline & Normal & 19 & 9.935324 & 1.7555 & & \\
\hline & Tumor & 399 & 6.986046 & 2.130077 & & \\
\hline \multirow[t]{3}{*}{ ZFPM2 } & & & & & $<0.001$ & Down \\
\hline & Normal & 19 & 9.218381 & 1.91825 & & \\
\hline & Tumor & 399 & 6.539535 & 1.752474 & & \\
\hline
\end{tabular}

'epithelial-to-mesenchymal transition' was the most remarkable one as defined by the FunRich: Functional Enrichment analysis tool, containing several genes ZFPM2, AKAP12, CLIC4, ZEB2, BNC2, CAV1, CXCL12, SOBP, TNS1, IGF1, SYNE1, PTX3 and WWTR1; among these genes, CAV1, CXCL12 and IGF1 were also identified as hub genes of miR-183-5p in BC by STRING: Functional protein association networks.
It has been fully demonstrated that miRNA expression levels could become reliable markers for the diagnosis and prognosis of cancers (36). miR-183-5p is one of the attractive cancer-relative miRNAs that has been reported to play important roles in various cancers with remarkably high or low expression levels compared with normal tissues. A remarkably high expression of miR-183-5p that could 
promote the proliferation and restrain apoptosis in cells through targeting PDCD4 was reported in human breast cancer tissues compared with that in the adjacent noncancerous tissues (20). A similar phenomenon and function of miR-183-5p was also reported in esophageal squamous cell carcinoma and glioblastoma multiforme (21-23). Upregulation of oncogenic miR-183-5p was reported to enhance the ability of proliferation and metastasis in human pancreatic adenocarcinoma cells probably via targeting the SOCS-6 gene (24). A notable lower expression of miR-183-5p was found in nasopharyngeal carcinoma and cervical cancer tissues, where miR-183-5p could act as the tumor suppressor by targeting MTA1 and MMP-9, respectively $(37,38)$. Reduced expression of miR-183-5p was discovered in pancreatic ductal adenocarcinoma tissues; and significantly associated with tumor grade, metastasis and TNM stage. Patients with low expression of miR-183-5p tended to have notably worse overall survival than those with high expression of miR-183-5p expression (38). Patients with low-expression of miR-183-5p tended to have a poor overall survival. miR183-5p was involved in cell proliferation by regulating the expression of Bmi-1 (39). Low-expression miR-183-5p was found in melanoma tissues and cells and was correlated with poor overall survival, while high-expression of miR-183-5p caused remarkable inhibition of cell growth in vitro and in vivo (25). Thus, miR-183-5p could play different roles in various cancers.

To date, only several studies were reported concerning the research of miR-183-5p in BC. It was validated that miR-183-5p expression in samples from patients with $B C$, including tissues $(26,40-42)$, urine $(27,43)$ and serum (29), were all prominently higher than that those in normal counterparts. In the present study, we revealed the consistent results in tissue samples.

Eissa et al performed ROC analysis of miR-183-5p expression in urine samples. However, only the sensitivity $(71.3 \%)$ and specificity $(88.9 \%)$ were provided (43). Yamada et al showed the result of ROC analysis $(\mathrm{AUC}=0.817 ; 95 \% \mathrm{CI}$ : $0.752-0.872$ ) with $74.0 \%$ sensitivity and $77.3 \%$ specificity, indicating a moderate diagnostic efficiency of miR-183-5p expression in urine, and they also found a significant correlation between miR-183-5p expression and clinical parameters, including tumor grade and pathological stage (P-value <0.05) (27). In our study, ROC curve analysis showed a robust diagnostic efficiency of miR-183-5p in BC tissues (AUC $=0.948$; 95\% CI: 0.919-0.977). The expression of miR-183-5p was markedly related to the diagnosis subtype, pathologic $\mathrm{T}$ stage and pathologic stage ( $\mathrm{P}$-value $<0.05)$. However, K-M curve analysis showed no prognostic efficiency of miR-183-5p, based on the data from TCGA, YM500v3 and cBioPortal.

miR-183-5p was conformed to affect the biological behavior of cells by targeting different kind of proteins in various types of cancers, such as regulating cell proliferation by targeting PDCD4 in breast (44) and esophageal cancer (21), and esophageal squamous cell carcinoma (22), inhibiting tumorigenesis by targeting MTA1 in nasopharyngeal carcinoma (37), promoting cell proliferation by targeting NEFL in glioblastoma multiforme (45), and suppressing retinoblastoma cell growth by targeting LRP6 (46). However, no study has reported the possible molecular mechanisms of miR-183-5p in BC. In the present, the potential target genes of miR-183-5p were obtained by the overlap of genes from 3 datasets, including the available predicting online tools, low-expression genes from TCGA and low-expression genes from microarray data after miR-183-5p mimic transfection.

The potential molecular mechanism of miR-183-5p in BC was explored. In total, 7,421 genes were predicted using the online predicting tool of miRwalk2.0. The low-expression genes from the RNA-seq data of TCGA with $\log 2$ FC <-1 were regarded as potential target genes of miR-183-5p, and 2,918 genes were involved. The GSE24782 microarray, which contained the data of differential-expressed genes after the overexpression of miR-183-5p in BOY and T24 cells, was reassessed to identify the downregulated genes with a fold change $<0.85 ; 3,163$ eligible genes were included. Consequently, 88 overlapped genes were identified and were more prone to be the target genes of miR-183-5p in BC. Next, bioinformatics analyses discovered that these potential target genes were enriched in several pathways involved in the tumorigenesis and development of BC. Forty-three genes were enriched in the pathway of cytoplasm, which ranked the 2 nd most significant pathways in the cellular component (CC). The most significant pathway indicated in molecular function (MF) was the pathway of cytoskeletal protein binding. Several significant pathways relative to signal transduction or cell communication were involved in biological process (BP), such as calcium-mediated signaling, cell communication and signal transduction. The pathway of epithelial-to-mesenchymal transition was the most enriched pathway in the biological pathway, playing a crucial role in tumor progression with genes of ZFPM2, AKAP12, CLIC4, ZEB2, BNC2, CAV1, CXCL12, SOBP, TNS1, IGF1, SYNE1, PTX3 and WWTR1. The expression of these 13 target genes was negatively correlated with the expression of miR-183-5p in BC tissues. miR-183-5p was conformed to target the tumor suppressor AKAP12 and plays an important role in human hepatocarcinogenesis (47). CAV1, CXCL12 and IGF1 were also identified as hub genes of miR183-5p in BC which may deeply affect the generation and development of $\mathrm{BC}$. However, rigorous experiments in vitro and in vivo are needed to confirm the potential molecular mechanism.

In summary, miR-183-5p may play critical roles in the tumorigenesis and development of $\mathrm{BC}$; however, the clinical function of miR-183-5p in BC urgently requires exploration. Furthermore, several crucial pathways for miR-183-5p in BC were predicted by bioinformatics analysis. However, validation of the real molecular mechanisms of miR-183-5p in BC by well-designed and rigorous functional experiments is still needed.

\section{Acknowledgements}

The present study was supported by the Guangxi Natural Science Fund for Innovation Research Team (2013GXNSFFA019002, 2016GXNSFGA38006), the Guangxi Collaborative Innovation Center for genomic and personalized medicine (201319), the Promoting Project of Basic Capacity for Young and Middleaged University Teachers in Guangxi (KY2016YB090), 
and the Innovation Project of Guangxi Graduate Education (YCBZ2017044).

\section{Competing interests}

The authors declare that they have no competing interests.

\section{References}

1. Ouyang H, Zhou Y, Zhang L and Shen G: Diagnostic value of microRNAs for urologic cancers: A systematic review and metaanalysis. Medicine 94: e1272, 2015.

2. Siegel RL, Miller KD, Fedewa SA, Ahnen DJ, Meester RGS, Barzi A and Jemal A: Colorectal cancer statistics, 2017. CA Cancer J Clin 67: 177-193, 2017.

3. Bao Z, Zhang W and Dong D: A potential prognostic lncRNA signature for predicting survival in patients with bladder urothelial carcinoma. Oncotarget 8: 10485-10497, 2017.

4. Berrondo C, Flax J, Kucherov V, Siebert A, Osinski T, Rosenberg A, Fucile C, Richheimer S and Beckham CJ: Expression of the long non-coding RNA HOTAIR correlates with disease progression in bladder cancer and is contained in bladder cancer patient urinary exosomes. PLoS One 11: e0147236, 2016.

5. Kang M, Jeong CW, Kwak C, Kim HH and Ku JH: Preoperative neutrophil-lymphocyte ratio can significantly predict mortality outcomes in patients with non-muscle invasive bladder cancer undergoing transurethral resection of bladder tumor. Oncotarget 8: 12891-12901, 2017.

6. Urquidi V, Netherton M, Gomes-Giacoia E, Serie DJ, Eckel-Passow J, Rosser CJ and Goodison S: A microRNA biomarker panel for the non-invasive detection of bladder cancer. Oncotarget 7: 86290-86299, 2016.

7. Xu X, Wang X, Fu B, Meng L and Lang B: Differentially expressed genes and microRNAs in bladder carcinoma cell line 5637 and T24 detected by RNA sequencing. Int J Clin Exp Pathol 8: 12678-12687, 2015.

8. Falzone L, Candido S, Salemi R, Basile MS, Scalisi A, McCubrey JA, Torino F, Signorelli SS, Montella M and Libra M: Computational identification of microRNAs associated to both epithelial to mesenchymal transition and NGAL/MMP-9 pathways in bladder cancer. Oncotarget 7: 72758-72766, 2016.

9. Cheng Y, Zhang X, Li P, Yang C, Tang J, Deng X, Yang X, Tao J, Lu Q and Li P: MiR-200c promotes bladder cancer cell migration and invasion by directly targeting RECK. Onco Targets Ther 9: 5091-5099, 2016

10. Egawa H, Jingushi K, Hirono T, Ueda Y, Kitae K, Nakata W, Fujita K, Uemura M, Nonomura $\mathrm{N}$ and Tsujikawa K: The miR-130 family promotes cell migration and invasion in bladder cancer through FAK and Akt phosphorylation by regulating PTEN. Sci Rep 6: 20574, 2016.

11. Ding M, Li Y, Wang H, Lv Y, Liang J, Wang J and Li C: Diagnostic value of urinary microRNAs as non-invasive biomarkers for bladder cancer: A meta-analysis. Int J Clin Exp Med 8: 15432-15440, 2015

12. Zhang X, Zhang Y, Liu X, Fang A, Li P, Li Z, Liu T, Yang Y, Du L and Wang C: MicroRNA-203 is a prognostic indicator in bladder cancer and enhances chemosensitivity to cisplatin via apoptosis by targeting Bcl-w and Survivin. PLoS One 10: e0143441, 2015.

13. Morais DR, Reis ST, Viana N, Piantino CB, Massoco C, Moura C, Dip N, Silva IA, Srougi M and Leite KR: The involvement of miR-100 in bladder urothelial carcinogenesis changing the expression levels of mRNA and proteins of genes related to cell proliferation, survival, apoptosis and chromosomal stability. Cancer Cell Int 14: 119, 2014

14. Wu WB, Wang W, Du YH, Li H, Xia SJ and Liu HT: MicroRNA-3713 regulates bladder cell invasion via MMP9. Sci Rep 6: 32374, 2016.

15. Cheng S, Liu J, Zhang Y, Lin Y, Liu Q, Li H, Huang J and Zhang P: Association detection between genetic variants in the microRNA binding sites of toll-like receptors signaling pathway genes and bladder cancer susceptibility. Int J Clin Exp Pathol 7: 8118-8126, 2014.

16. Wang H, Zhang W, Zuo Y, Ding M, Ke C, Yan R, Zhan H, Liu J and Wang J: miR-9 promotes cell proliferation and inhibits apoptosis by targeting LASS2 in bladder cancer. Tumour Biol 36: 9631-9640, 2015.

17. Zhou M, Wang S, Hu L, Liu F, Zhang Q and Zhang D: miR199a-5p suppresses human bladder cancer cell metastasis by targeting CCR7. BMC Urol 16: 64, 2016.
18. Shang A, Yang M, Shen F, Wang J, Wei J, Wang W, Lu W, Wang $C$ and Wang C: MiR-1-3p suppresses the proliferation, invasion and migration of bladder cancer cells by up-regulating SFRP1 expression. Cell Physiol Biochem 41: 1179-1188, 2017.

19. Pignot G, Cizeron-Clairac G, Vacher S, Susini A, Tozlu S, Vieillefond A, Zerbib M, Lidereau R, Debre B, AmsellemOuazana $\mathrm{D}$ and Bieche I: microRNA expression profile in a large series of bladder tumors: Identification of a 3-miRNA signature associated with aggressiveness of muscle-invasive bladder cancer. Int J Cancer 132: 2479-2491, 2013.

20. Gu W, Gao T, Shen J, Sun Y, Zheng X, Wang J, Ma J, Hu XY, $\mathrm{Li} \mathrm{J}$ and $\mathrm{Hu}$ MJ: MicroRNA-183 inhibits apoptosis and promotes proliferation and invasion of gastric cancer cells by targeting PDCD4. Int J Clin Exp Med 7: 2519-2529, 2014.

21. Yang M, Liu R, Li X, Liao J, Pu Y, Pan E, Yin L and Wang Y: miRNA-183 suppresses apoptosis and promotes proliferation in esophageal cancer by targeting PDCD4. Mol Cells 37: 873-880, 2014.

22. Ren LH, Chen WX, Li S, He XY, Zhang ZM, Li M, Cao RS, Hao B, Zhang HJ, Qiu HQ and Shi RH: MicroRNA-183 promotes proliferation and invasion in oesophageal squamous cell carcinoma by targeting programmed cell death 4 . Br J Cancer 111: 2003-2013, 2014

23. Li C, Deng L, Zhi Q, Meng Q, Qian A, Sang H, Li X and Xia J: MicroRNA-183 functions as an oncogene by regulating PDCD4 in gastric cancer. Anticancer Agents Med Chem 16: 447-455, 2016.

24. Miao F, Zhu J, Chen Y, Tang N, Wang X and Li X: MicroRNA183-5p promotes the proliferation, invasion and metastasis of human pancreatic adenocarcinoma cells. Oncol Lett 11: 134-140, 2016.

25. Sun Y, Cheng H, Wang G, Yu G, Zhang D, Wang Y, Fan W and Yang W: Deregulation of miR-183 promotes melanoma development via lncRNA MALAT1 regulation and ITGB1 signal activation. Oncotarget 8: 3509-3518, 2017.

26. Han Y, Chen J, Zhao X, Liang C, Wang Y, Sun L, Jiang Z, Zhang Z, Yang R, Chen J, et al: MicroRNA expression signatures of bladder cancer revealed by deep sequencing. PLoS One 6: e18286, 2011.

27. Yamada Y, Enokida H, Kojima S, Kawakami K, Chiyomaru T, Tatarano S, Yoshino H, Kawahara K, Nishiyama K, Seki N and Nakagawa M: MiR-96 and miR-183 detection in urine serve as potential tumor markers of urothelial carcinoma: Correlation with stage and grade, and comparison with urinary cytology. Cancer Sci 102: 522-529, 2011.

28. Wei S, Bing Z, Yao Y, Master SR and Gupta P: Higher expression of miR-182 in cytology specimens of high-grade urothelial cell carcinoma: A potential diagnostic marker. Acta Cytol 59: 109-112, 2015.

29. Scheffer AR, Holdenrieder S, Kristiansen G, von Ruecker A, Müller SC and Ellinger J: Circulating microRNAs in serum: Novel biomarkers for patients with bladder cancer? World J Urol 32: 353-358, 2014.

30. Robertson AG, Kim J, Al-Ahmadie H, Bellmunt J, Guo G, Cherniack AD, Hinoue T, Laird PW, Hoadley KA, Akbani R, et al: Comprehensive molecular characterization of muscle-invasive bladder cancer. Cell 171: 540-556.e25, 2017.

31. Li QQ, Hsu I, Sanford T, Railkar R, Balaji N, Sourbier C, Vocke C, Balaji KC and Agarwal PK: Protein kinase D inhibitor CRT0066101 suppresses bladder cancer growth in vitro and xenografts via blockade of the cell cycle at G2/M. Cell Mol Life Sci: Oct 25, 2017 (Epub ahead of print). doi: 10.1007/s00018-0172681-z.

32. Robinson MD, McCarthy DJ and Smyth GK: edgeR: A bioconductor package for differential expression analysis of digital gene expression data. Bioinformatics 26: 139-140, 2010.

33. Zeng JH, Liang L, He RQ, Tang RX, Cai XY, Chen JQ, Luo DZ and Chen G: Comprehensive investigation of a novel differentially expressed lncRNA expression profile signature to assess the survival of patients with colorectal adenocarcinoma. Oncotarget 8: 16811-16828, 2017.

34. Benito-Martin A and Peinado H: FunRich proteomics software analysis, let the fun begin! Proteomics 15: 2555-2556, 2015.

35. Pathan M, Keerthikumar S, Ang CS, Gangoda L, Quek CY, Williamson NA, Mouradov D, Sieber OM, Simpson RJ, Salim A, et al: FunRich: An open access standalone functional enrichment and interaction network analysis tool. Proteomics 15: 2597-2601, 2015. 
36. Xu F, Zhang H, Su Y, Kong J, Yu H and Qian B: Up-regulation of microRNA-183-3p is a potent prognostic marker for lung adenocarcinoma of female non-smokers. Clin Transl Oncol 16: 980-985, 2014.

37. Wang G, Wang S and Li C: MiR-183 overexpression inhibits tumorigenesis and enhances DDP-induced cytotoxicity by targeting MTA1 in nasopharyngeal carcinoma. Tumour Biol 39: $1010428317703825,2017$.

38. Fan D, Wang Y, Qi P, Chen Y, Xu P, Yang X, Jin X and Tian X: MicroRNA-183 functions as the tumor suppressor via inhibiting cellular invasion and metastasis by targeting MMP-9 in cervical cancer. Gynecol Oncol 141: 166-174, 2016.

39. Zhou L, Zhang WG, Wang DS, Tao KS, Song WJ and Dou KF: MicroRNA-183 is involved in cell proliferation, survival and poor prognosis in pancreatic ductal adenocarcinoma by regulating Bmi-1. Oncol Rep 32: 1734-1740, 2014.

40. Chen YH, Wang SQ, Wu XL, Shen M, Chen ZG, Chen XG, Liu YX, Zhu XL, Guo F, Duan XZ, et al: Characterization of microRNAs expression profiling in one group of Chinese urothelial cell carcinoma identified by Solexa sequencing. Urol Oncol 31: 219-227, 2013.

41. Ichimi T, Enokida H, Okuno Y, Kunimoto R, Chiyomaru T, Kawamoto K, Kawahara K, Toki K, Kawakami K, Nishiyama K, et al: Identification of novel microRNA targets based on microRNA signatures in bladder cancer. Int J Cancer 125: 345-352, 2009.

42. Friedman JM, Liang G,Liu CC, Wolff EM, Tsai YC, Ye W, Zhou X and Jones PA: The putative tumor suppressor microRNA-101 modulates the cancer epigenome by repressing the polycomb group protein EZH2. Cancer Res 69: 2623-2629, 2009.

43. Eissa S, Matboli M, Hegazy MG, Kotb YM and Essawy NO Evaluation of urinary microRNA panel in bladder cancer diagnosis: Relation to bilharziasis. Transl Res 165: 731-739, 2015.
44. Cheng Y, Xiang G, Meng Y and Dong R: MiRNA-183-5p promotes cell proliferation and inhibits apoptosis in human breast cancer by targeting the PDCD4. Reprod Biol 16: 225-233, 2016.

45. Wang ZY, Xiong J, Zhang SS, Wang JJ, Gong ZJ and Dai MH: Up-regulation of microRNA-183 promotes cell proliferation and invasion in glioma by directly targeting NEFL. Cell Mol Neurobiol 36: 1303-1310, 2016.

46. Wang J, Wang X, Li Z, Liu H and Teng Y: MicroRNA-183 suppresses retinoblastoma cell growth, invasion and migration by targeting LRP6. FEBS J 281: 1355-1365, 2014.

47. Goeppert B, Schmezer P, Dutruel C, Oakes C, Renner M, Breinig M, Warth A, Vogel MN, Mittelbronn M, Mehrabi A, et al: Down-regulation of tumor suppressor A kinase anchor protein 12 in human hepatocarcinogenesis by epigenetic mechanisms. Hepatology 52: 2023-2033, 2010.

(i) $($ ) This work is licensed under a Creative Common Attribution-NonCommercial-NoDerivatives 4.0 International (CC BY-NC-ND 4.0) License. 